\title{
Imaging mass cytometry for high- dimensional tissue profiling in the eye
}

\author{
Anja Schlecht ${ }^{1,2}$, Stefaniya Boneva ${ }^{1}$, Henrike Salie ${ }^{3}$, Saskia Killmer ${ }^{3}$, Julian Wolf ${ }^{1}$, Rozina Ida Hajdu ${ }^{1,4}$, \\ Claudia Auw-Haedrich', Hansjürgen Agostini', Thomas Reinhard', Günther Schlunck', Bertram Bengsch ${ }^{3}$ and \\ Clemens AK Lange ${ }^{1^{*}}$
}

\begin{abstract}
Background: Imaging mass cytometry (IMC) combines the principles of flow cytometry and mass spectrometry (MS) with laser scanning spatial resolution and offers unique advantages for the analysis of tissue samples in unprecedented detail. In contrast to conventional immunohistochemistry, which is limited in its application by the number of possible fluorochrome combinations, IMC uses isoptope-coupled antibodies that allow multiplex analysis of up to 40 markers in the same tissue section simultaneously.

Methods: In this report we use IMC to analyze formalin-fixed, paraffin-embedded conjunctival tissue. We performed a 18-biomarkers IMC analysis of conjunctival tissue to determine and summarize the possibilities, relevance and limitations of IMC for deciphering the biology and pathology of ocular diseases.

Results: Without modifying the manufacturer's protocol, we observed positive and plausible staining for 12 of 18 biomarkers. Subsequent bioinformatical single-cell analysis and phenograph clustering identified 24 different cellular clusters with distinct expression profiles with respect to the markers used.

Conclusions: IMC enables highly multiplexed imaging of ocular samples at subcellular resolution. IMC is an innovative and feasible method, providing new insights into ocular disease pathogenesis that will be valuable for basic research, drug discovery and clinical diagnostics.
\end{abstract}

Keywords: Imaging mass cytometry, IMC, multi-dimensional cellular profiling, conjunctival melanoma

\section{Background}

For several decades, immunohistochemistry (IHC) has been applied as the gold standard for tissue-specific localization of protein expression for diagnosis of various eye diseases including tumors such as conjunctival melanoma [1]. Existing IHC methods use antibodies tagged with fluorophores or enzyme reporters that generate colored pigments. Using sophisticated equipment, simultaneous staining of up to seven markers for diagnostics is possible [2]. However, due to fluorophore reporter

\footnotetext{
* Correspondence: clemens.lange@uniklinik-freiburg.de

${ }^{1}$ Faculty of Medicine, Eye Center, University of Freiburg, Killianstrasse 5, 79106 Freiburg, Germany

Full list of author information is available at the end of the article
}

emission overlap, tissue is usually stained with only one to three fluorochrome-tagged antibodies, which is feasible using regular equipment. The number of proteins to be stained is also constrained by the small number of possible donor species of the antibodies. These limitations have so far prevented a multiplex IHC approach in the routine clinical setting.

CyTOF (cytometry by time of flight) analysis was first described in 2009 and combines flow cytometry and mass spectrometry (MS) analysis [3]. This new method uses antibodies or oligonucleotide probes labeled with unique and stable transition element metal isotopes, the signal of which is subsequently amplified by a polymeric metal chelating reagent or metal nanoparticles [3-5]. 
While this method was previously only applicable for single cell suspensions, the recent combination of mass cytometry with conventional immunohistochemistry (known as Imaging Mass Cytometry, IMC) has led to a next-generation IHC approach that allows the simultaneous staining and analysis of multiple markers [6]. Current mass cytometry instrumentation includes up to 121 different mass detection channels, enabling concomitant multiplex imaging without the risk for overlapping reporter emission [7]. High-resolution scanning laser ablation followed by mass cytometry facilitates highly multiplexed imaging of various tissue types at subcellular resolution [6] using formalin-fixed and paraffin-embedded (FFPE)-material stained with metaltagged antibodies. This allows for in-depth characterization of diseased tissue to improve diagnostics und treatment options.

In this report, we present a detailed description of the IMC methodology and show the first explorative data on a multiplex characterization approach of ocular tissue at the single cell level. We demonstrate that IMC combined with bioinformatics enables the simultaneous staining and quantification of 18 different proteins in a single tissue section of healthy conjunctival and conjunctival melanoma samples, providing unprecedented insights into disease processes at the cellular level.

\section{Methods}

\section{Patients}

Conjunctival samples were obtained from patients undergoing retinal detachment surgery $(n=1)$ or conjunctival melanoma resection $(n=1)$ at the Eye Center of the University of Freiburg. Ethics approval was granted from Ethics Committee of the Albert-LudwigsUniversity Freiburg (approval number 481/19).

\section{Tissue processing}

Conjunctival samples (healthy conjunctiva and conjunctival melanoma) were fixed in $4 \%$ formalin for $12 \mathrm{~h}$ immediately after surgery and subsequently dehydrated by ascending alcohol series $(70 \%, 80 \%, 2 \times 96 \%$ for $30 \mathrm{~min}$, $2 \times 100 \%$ for $15 \mathrm{~min})$. After two incubation steps in xylene (one hour each), the samples were incubated in liquid paraffin for $4 \mathrm{~h}$ and subsequently embedded. For staining, $6 \mu \mathrm{m}$ thick sections were made and placed on slides. Prior to staining, paraffin slides were incubated at $60{ }^{\circ} \mathrm{C}$ for $90 \mathrm{~min}$ and deparaffinized in xylene $(2 \times$ $10 \mathrm{~min})$. After rehydration in descending series of ethanol $(2 \times 100 \%, 95 \%, 80 \% 5$ min each) slides were washed in TBS for $5 \mathrm{~min}$. Heat-induced antigen retrieval was performed using DAKO EnvisionFlex target retrieval solution (high pH, Agilent Technologies, Santa Clara, CA) for incubation at $95{ }^{\circ} \mathrm{C}, 30 \mathrm{~min}$ in a pressure cooker. After cooling down for $20 \mathrm{~min}$ and washing in
TBS, slides were blocked in 3 \%BSA in TBS for $60 \mathrm{~min}$ at room temperature. The Maxpar Human ImmunoOncology IMC ${ }^{\mathrm{ma}}$ Panel Kit (Fluidigm, San Francisco, CA) was used to stain the sections. A complete list of antibodies, clones and conjugated metals included in the kit is shown in Table 1. Before staining, we performed a dilution series of all antibodies (1:50, 1:100, 1:200, 1:400, 1: 800 and 1:1600) to optimize the protocol. Since the dilution 1:800 gave the most specific staining pattern, we subsequently chose this dilution of antibodies for staining. Diluted antibodies $(1: 800)$ were applied to sections simultaneously using an antibody mix and incubated over night at $4{ }^{\circ} \mathrm{C}$ in a hydration chamber. After washing in TBS $(3 \times 5 \mathrm{~min})$, iridium-intercalator solution $(1: 2000$ in TBS) was applied to sections for $5 \mathrm{~min}$ and slides were washed $3 \times 5 \mathrm{~min}$ in TBS afterwards. After $30 \mathrm{~min}$ drying at room temperature, sections were subjected to laser ablation and acquisition.

\section{Image acquisition}

One image per sample was acquired using the Hyperion Imaging Mass Cytometry ${ }^{\mathrm{Tm}}$ (IMC ${ }^{\mathrm{Tm}}$, Fluidigm) after tuning the instrument according to manufacturer's instructions. Regions of interest were laser-ablated spot-by-spot at $200 \mathrm{~Hz}$ resulting in a pixel size/resolution of $1 \mu \mathrm{m}^{2}$. Preprocessing of the raw data was performed using the CyTOF software v7.0 (Fluidigm). Visualization of images was conducted using MCD Viewer v1.0.560.6 (Fluidigm).

Table 1 Antibodies, clones and conjugates

\begin{tabular}{lll}
\hline Target & Clone & Metal \\
\hline CD20 & H1 & $161 \mathrm{Dy}$ \\
CD3 & Poly & $170 \mathrm{Er}$ \\
CD4 & EPR6855 & $156 \mathrm{Gd}$ \\
CD45Ro & UCJL1 & $173 \mathrm{Yb}$ \\
CD68 & KP1 & $159 \mathrm{~Tb}$ \\
CD8a & C8/144B & $162 \mathrm{Dy}$ \\
FoxP3 & $236 \mathrm{~A} / \mathrm{E} 7$ & $155 \mathrm{Gd}$ \\
Pan-keratin & C11 & $148 \mathrm{Nd}$ \\
Granzyme B & EPR20129-217 & $167 \mathrm{Er}$ \\
Ki-67 & B56 & $168 \mathrm{Er}$ \\
PD-1 & EPR4877(2) & $165 \mathrm{Ho}$ \\
PD-L1 & SP142 & $150 \mathrm{Nd}$ \\
a-SMA & $1 \mathrm{~A} 4$ & $141 \mathrm{Pr}$ \\
Collagen type I & Poly & $169 \mathrm{Tm}$ \\
E-cadherin & $24 E 10$ & $158 \mathrm{Gd}$ \\
Histone H3 & D1H2 & $171 \mathrm{Yb}$ \\
Vimentin & D21H3 & $143 \mathrm{Nd}$ \\
Nucleic acid & & $191 / \mathrm{lr} / 193 \mathrm{lr}$ \\
\hline
\end{tabular}




\section{Segmentation and data analysis}

For analysis of multiplex imaging data, such as ion counts per marker, segmentation masks are essential to extract single cell measurements [8]. IMC data was processed as previously described [8]. In brief, text files generated in the process of data acquisition were converted into tiff image stacks using a Python script (https:// github.com/BodenmillerGroup/imctools). Hereafter, segmentation masks were developed by using the ilastik software [9] (Version 1.3.2) to designate nuclei, cytoplasm and background fractions. Subsequently the probability maps were uploaded into CellProfiler [10] (Version 3.1.8) to create cell masks which were used to extract single-cell information. The single cell data was normalized to the 99th percentile for Phenograph clustering, which was subsequently performed according to an algorithm implemented in histoCAT[11] (Version 1.76). Data was visualized using histoCAT. t-SNE dimensionality reduction [12] and Phenograph cluster plots [13] were generated.

\section{Results}

Application of imaging mass cytometry to ocular tissue

To facilitate the future use of IMC for the examination and diagnosis of ocular tissue, such as conjunctival melanomas, we established a workflow for preclinical and clinical routine, which is shown in Fig. 1. After tissue resection for biopsies or surgery, we immediately fixed the tissue with formalin and embedded it in paraffin and finally cut it into $6 \mu \mathrm{m}$ thick sections with a microtome. The staining of the sections was performed using the Maxpar Human Immuno-Oncology IMC ${ }^{\text {тм }}$ Panel Kit which was easy to perform within two days according to the manufacturer's protocol using conventional laboratory equipment. An additional day should be scheduled for measuring the sections with the Hyperion Imaging Mass Cytometry ${ }^{\mathrm{ma}}$ system. Thus, this method can be performed in about three days from the time of tissue collection to the generation of the images, which is comparable to the time required for conventional immunohistochemistry, considering the much higher information content due to the simultaneous use of the high number of antibodies on only one tissue slide.

\section{Evaluation of staining success using Maxpar ${ }^{\circledR}$ Human Immuno-Oncology IMC ${ }^{\text {TM }}$ Panel Kit on ocular tissue sections}

The Maxpar Human Immuno-Oncology IMC ${ }^{\mathrm{Tm}}$ Panel Kit contained 17 markers including structural markers, immune activation and proliferation markers, as well as an intercalator (labeling of nucleic acid) to be used simultaneously. Following the manufacturer's instructions, we observed positive and distinct staining of $12 / 17$ markers ( $\alpha$-SMA, Ki-67, CD8a, CD45Ro, CD68, FoxP3,

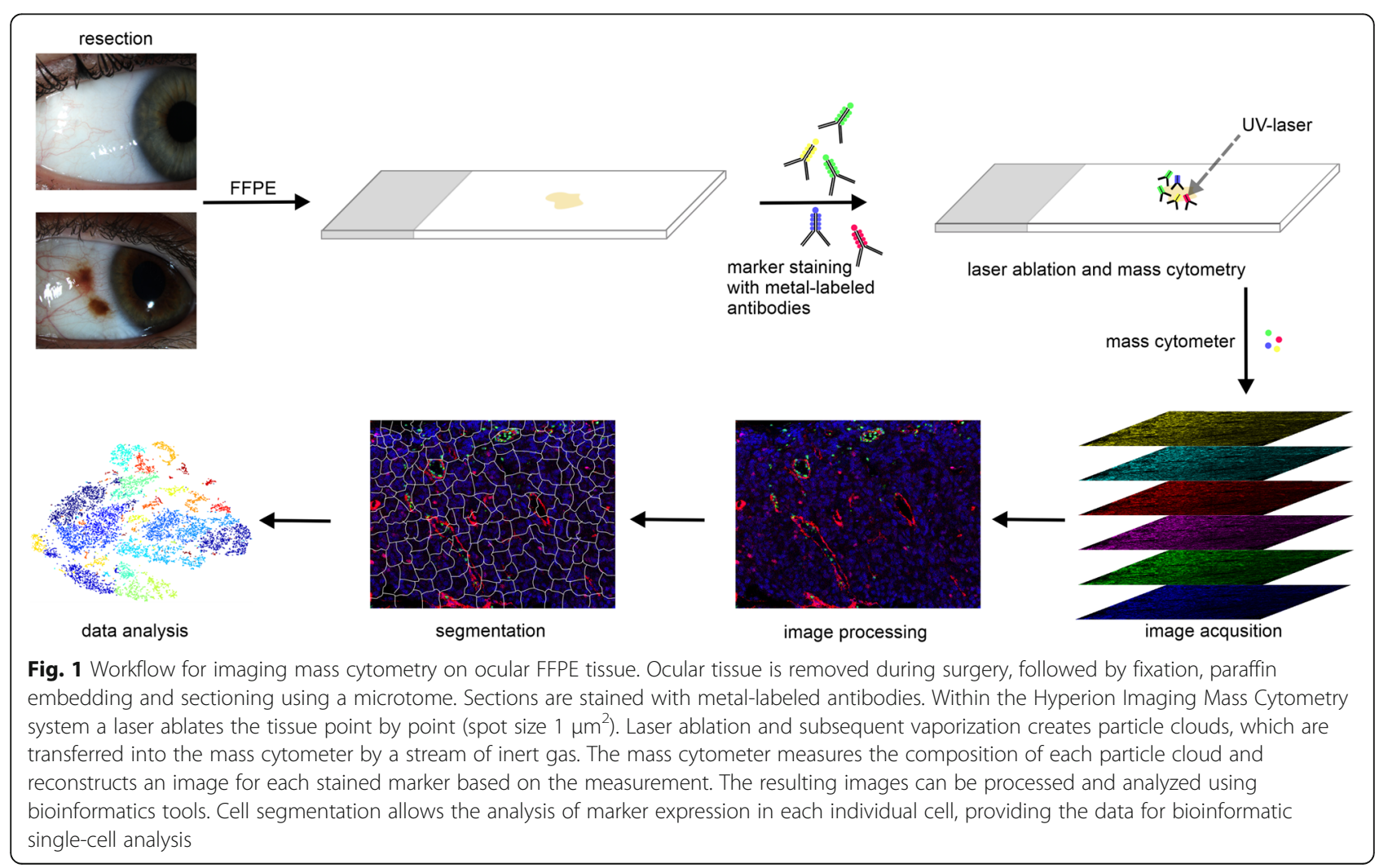


histone H3, granzyme B, collagen I, E-cadherin, vimentin, pan-keratin, Fig. 2). In contrast, rather diffuse or absent staining of five markers that worked well in control tissues (CD3, CD4, CD20, PD-1, PD-L1, Suppl. Figure 1) was observed in the conjunctiva. The latter is consistent with evidence from the literature showing that PD-1 and PD-L1 expression is very low or absent in conjunctival melanoma tumor cells $[14,15]$. However, we cannot be confident in this exploratory study whether the lack of staining is due to the absence of these five markers in the conjunctiva or to technical reasons. Therefore, in the following we only refer to the 12 markers that we were able to stain successfully without major changes to the manufacturer's protocol.

\section{Comparison of healthy conjunctiva and conjunctival melanoma}

In the next step, we investigated markers in detail that are discussed to play a role in the context of conjunctival melanoma. For this purpose, we analyzed Ki-67 as a proliferation marker [16], CD68 as an myeloid cell marker [17], $\alpha$-SMA as a marker for perivascular cells, myofibroblasts and smooth muscle cells $[18,19]$ and granzyme $\mathrm{B}$, which is expressed in cytotoxic $\mathrm{T}$ cells [20] in the healthy conjunctiva and in conjunctival melanoma (Fig. 3). The direct comparison of the two tissues regarding these markers revealed considerable differences in immunoreactivity between the two conditions. As expected, hardly any Ki-67, or granzyme B positive cells were found in the healthy conjunctiva, but CD68 positive myeloid cells and $\alpha$-SMA-positive perivascular smooth muscle cells were readily detected (Fig. 3, upper panel). In contrast, melanoma tissue showed a massive accumulation of CD68-positive immune cells, many proliferating cells and an increased immunoreactivity for granzyme-B and $\alpha$-SMA. (Fig. 3, lower panel). In summary, analysis of selected markers showed clear differences between the physiological state of the conjunctiva and conjunctival melanoma, which further underlines the validity of this method.

\section{High-dimensional cellular profiling}

To gain a deeper insight into cellular phenotypes and how they differ in healthy conjunctiva compared to conjunctival melanoma, we performed segmentation of images into single cells, which allows the analysis of marker expression in each individual cell, providing high dimensional data for bioinformatic single-cell analysis. The single cell data was normalized to the 99th percentile for Phenograph clustering, which was subsequently performed according to an algorithm implemented in histoCAT [11]. The analysis identified 24 different cellular clusters with distinct expression profiles with respect to the markers used (Fig. 4B). A heatmap illustrating the average marker expression in each cluster is presented in supplemental Fig. 2. Further analysis revealed that some of the clusters can be attributed exclusively to healthy conjunctiva, while other clusters contained predominantly cells from conjunctival melanoma (Fig. 4 A). When focusing on the expression level of distinct factors, we found that, for example, Ki-67 was highly expressed in a cluster composed almost exclusively of melanoma cells (Fig. 4 C). Pankeratin, on the other hand, was mainly expressed in cells derived from healthy conjunctiva (Fig. 4D). These results are consistent with the literature [21-26], clearly demonstrate the validity of IMC, and support the application of the method in ocular research and diagnostics.

\section{Discussion}

Histological visualization of protein expression is an important diagnostic pillar for assessment of various eye diseases [1]. Conventional immunohistochemistry, however, is limited by the small number of available fluorophores, light sources and filters, but also by the scarce number of possible donor species of antibodies, preventing multiplex protein detection. In this study, we introduce Imaging Mass Cytometry (IMC) to the field of ophthalmopathology and show the first explorative data on a multiplex characterization approach of ocular tissue at the single cell level. We demonstrate that IMC combined with bioinformatics enables the simultaneous staining and quantification of 12 different proteins in a single tissue section at the cellular level, providing unprecedented insights into disease processes.

Imaging mass cytometry was first described in 2014 by Bernd Bodenmiller's group and allows the simultaneous staining of several dozen markers by combining conventional immunohistochemistry with the CyTOF mass cytometer [6]. This technique allows a multidimensional analysis of protein expression in subcellular resolution, which is a great innovation in research as well as in clinical routine diagnostics. A major advantage of this method is that sample preparation is similar to conventional immunohistochemistry, both in terms of sample processing and time investment [6]. Since the technique is based on the detection of metal isotopes and not fluorophore-conjugated antibodies, background autofluorescence is not an issue in this setup and amplification of measured signals is not necessary [6]. A further advantage is the high resolution $(1 \mu \mathrm{m})$ of the reconstructed images, which is comparable to light microscopic images and surpasses that of other techniques such as MALDI (Matrix Assisted Laser Desorption/Ionization) [27]. The validity of the method is impressive and several studies have shown that conjugation of antibodies with metal isotopes does not affect antigen binding properties and IMC staining patterns 


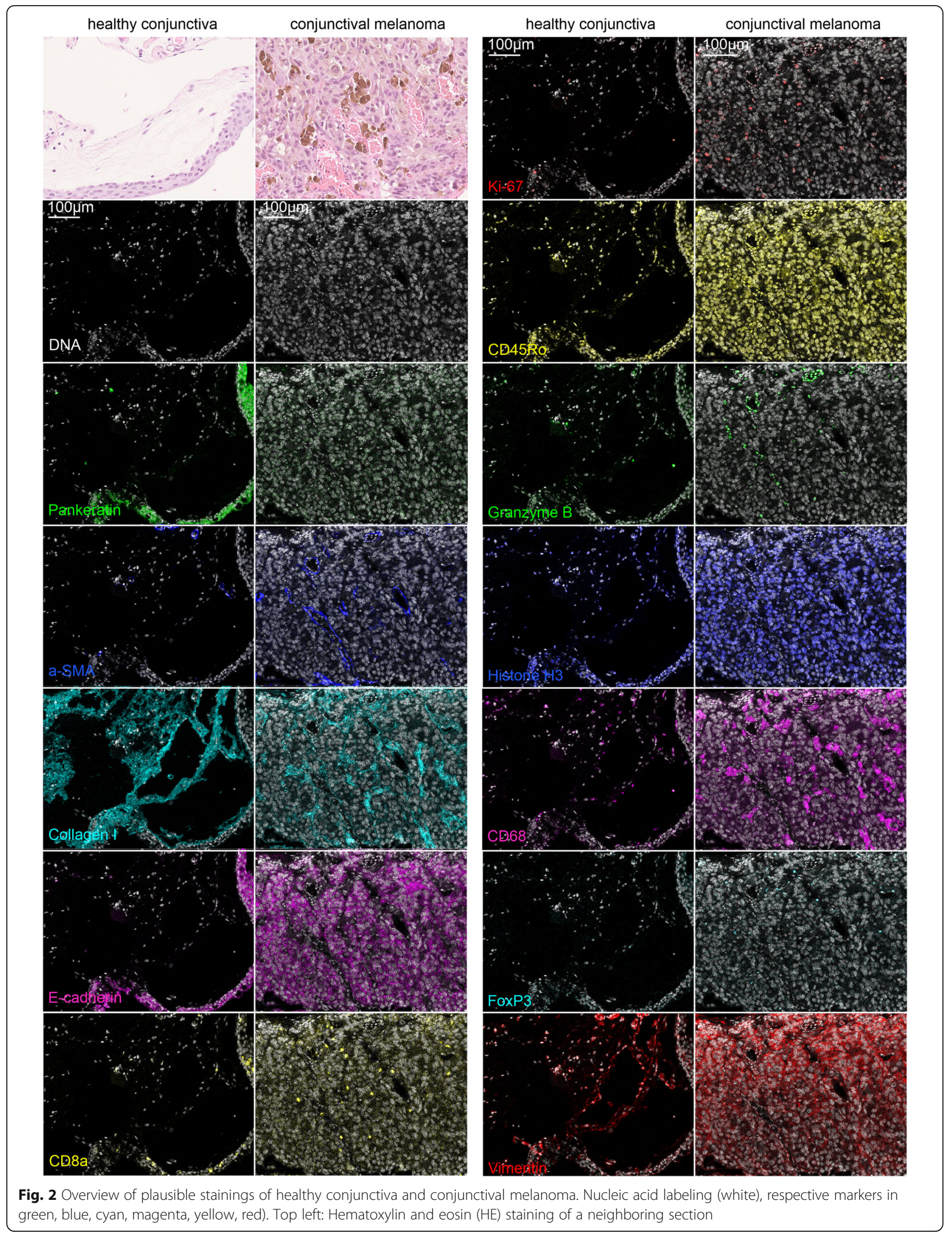




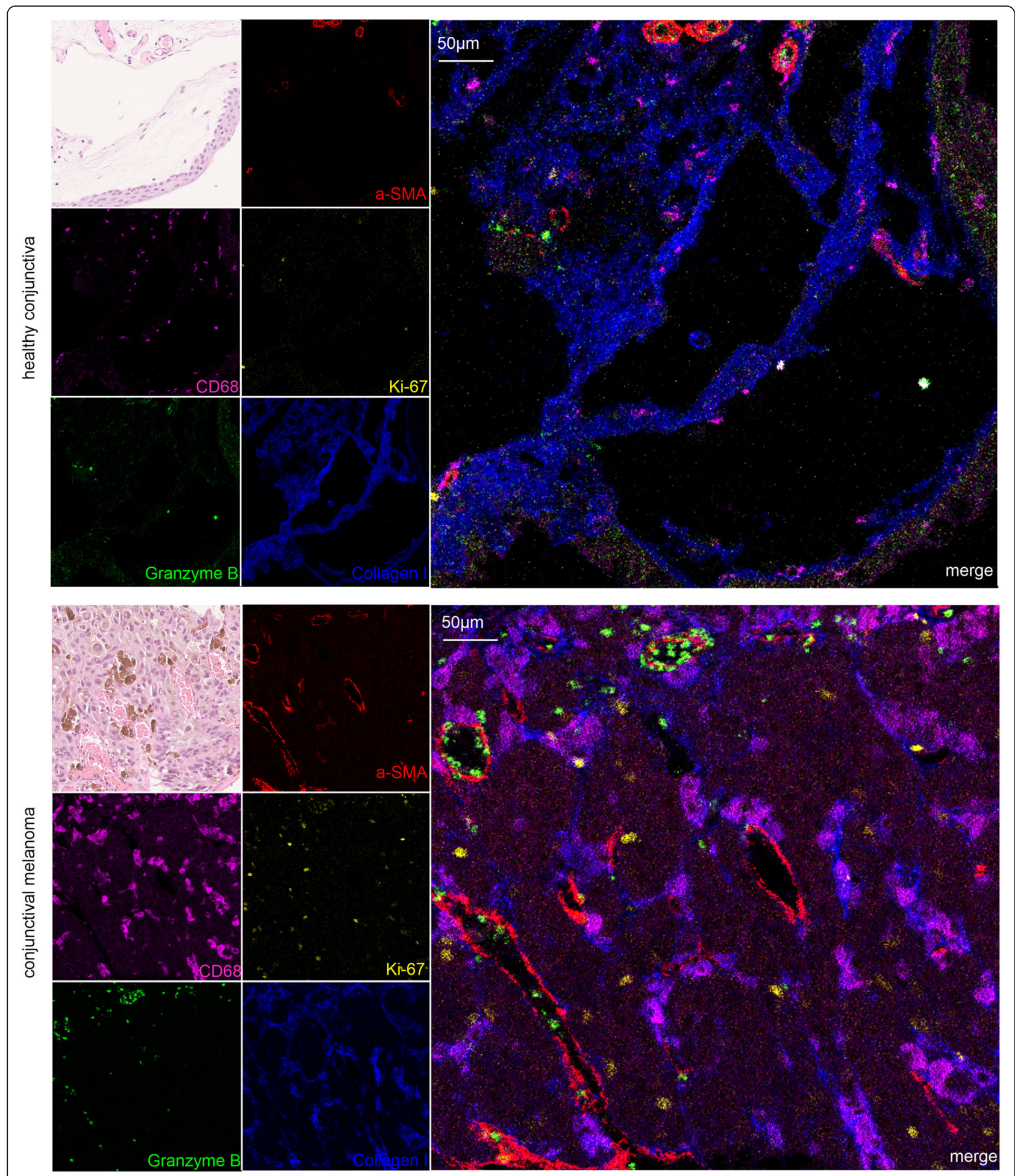

Fig. 3 Detection of melanoma-related markers. Immunoreactivity for CD68 (magenta), Ki-67 (yellow) granzyme B (green), a-SMA (smooth muscle actin, red) and collagen I (blue) in the healthy conjunctiva (upper panel) and conjunctival melanoma (lower panel). $\mathrm{H} \& \mathrm{E}$ staining of a neighboring section is shown in the upper left corner

could be reproduced by regular IHC [6, 28]. A recent publication even describes a way to visualize and analyze proteins and RNA transcripts simultaneously on a single tissue section using IMC and a metal tag-based in situ protocol [5, 29]. This approach builds a bridge between transcriptomic and proteomic expression, which may 


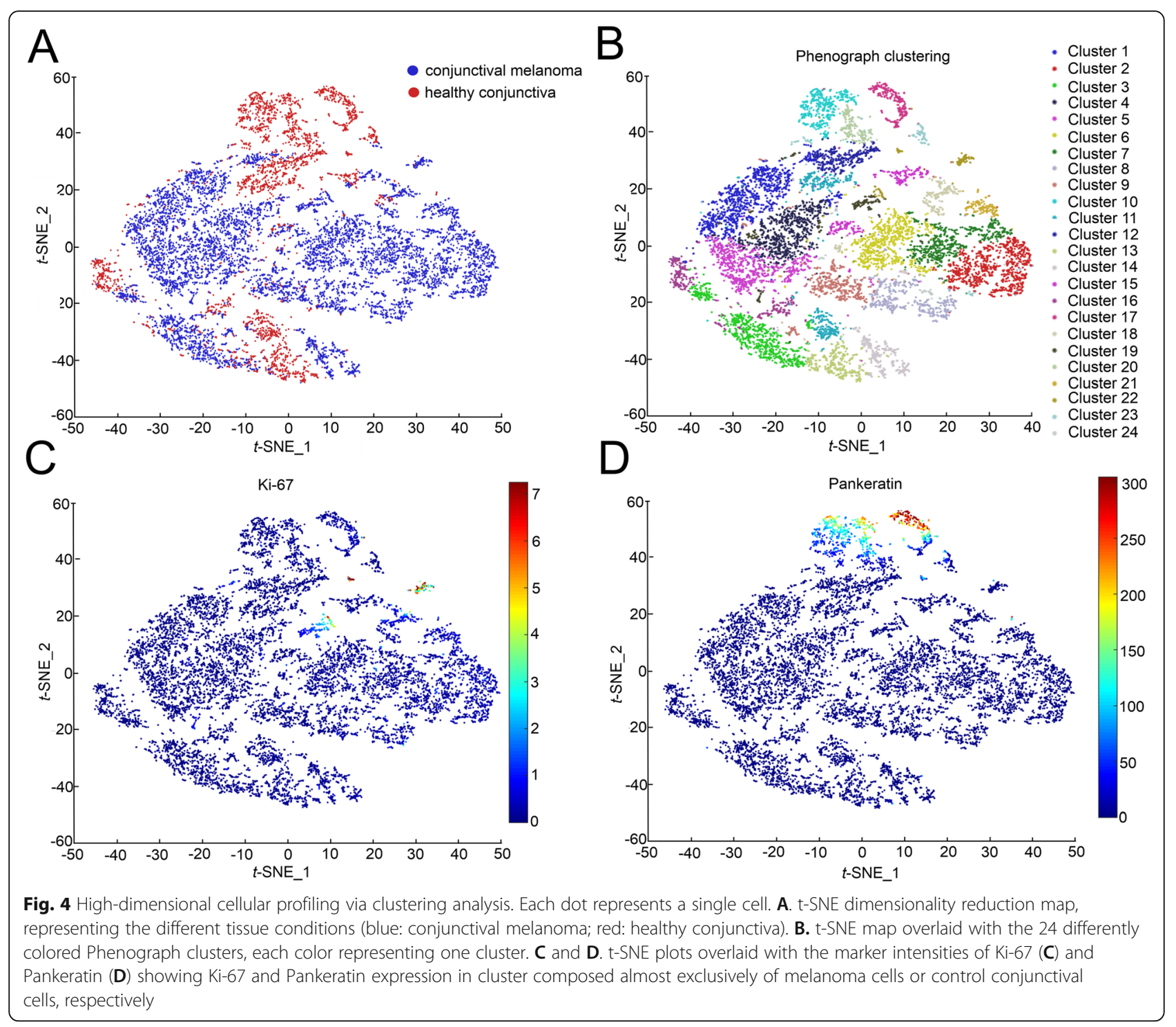

massively increase the information content of patient samples and create a new level of tissue analysis [5].

Although IMC has great advantages and has developed remarkably over the last years, it still has some limitations that need to be pointed out. The successful analysis of tissue sections with this method is based, as with conventional IHC, on the specificity of the antibodies used. Firstly, antibodies against the proteins of interest must be available, secondly, a plausible antigen-antibody interaction is a prerequisite for the successful application in IMC [6]. Furthermore, in conventional IHC, the performance of each individual antibody can be optimized by modifying the staining protocol with respect to demasking procedure, incubation time or blocking. In a multiplex approach, where up to 40 antibodies are stained in parallel, different protocols may be unfeasible [6].
Although existing instruments can theoretically measure more than 100 different channels, the multiplex application is currently still restricted to a few dozen due to limited availability of suitable isotopes $[3,6,30]$. Even though IMC allows multidimensional analysis at the single cell level, which is a great innovation for example in tumor research, the analysis of tissue sections is only a snapshot and cannot represent the dynamic processes that occur during tumor development.

It is also important to emphasize that IMC is not an unbiased approach to the analysis of the total proteome, as the information content of the data is clearly limited by the pre-selection of markers to be stained and, furthermore, might be narrowed by measurement speed. Since the data acquisition takes two hours per square millimeter of tissue, analysis of smaller regions is often preferred due to time constraints [31]. As tumor tissues 
are frequently characterized by high heterogeneity, the analysis might be biased by a reduced representativeness [30]. Not only the measurement, but also the analysis of the generated data requires a considerable amount of time and financial effort due to its multidimensionality. Therefore, a routine diagnostic application of IMC in daily practice may currently still be challenging to implement.

Even if IMC at present still has some limitations, such as the extensive data acquisition time, the number of isotopes available or the complex bioinformatic analysis, it can be assumed that this will change within the next few years. Lower costs and innovative developments, which increase availability of isotopes may lead to a situation where in the future more than 100 markers can be measured in less than one hour [6].

\section{Conclusions}

In summary, Imaging Mass Cytometry represents a highly multiplexed imaging method which allows the analysis of small ocular tissue samples with subcellular resolution in so far unpreceded detail. Thus, IMC can be considered as the next generation immunohistochemistry, which enables the investigation of molecular changes in neoplastic and degenerative eye diseases and may even play a role in clinical diagnostics in the future.

\section{Abbreviations}

CyTOF: Cytometry by time of flight; FFPE: Formalin-fixed and paraffinembedded; IHC: Immunohistochemistry; IMC: Imaging mass cytometry; MS: Mass cytometry

\section{Supplementary information}

The online version contains supplementary material available at https://doi. org/10.1186/s12886-021-02099-8.

Additional file 1 Supplemental Fig. 1: Overview of markers showing diffuse or absent staining in healthy conjunctiva and/or conjunctival melanoma. Nucleic acid labeling is shown in blue, respective markers in white.

Additional file 2 Supplemental Fig. 2: Heatmap illustrating average marker expression in each cluster.

\section{Acknowledgements}

We would like to thank Gabriele Prinz, Sylvia Zeitler and Brigitte Joos for excellent technical assistance.

\section{Authors' contributions}

AS, HS,SK and RIH performed the experiments, SB, AS and JW analyzed the data, CAW provided material, HA, TR, GS and BB helped to interpret the data, $\mathrm{AS}$ and $\mathrm{CL}$ supervised the project and wrote the manuscript. All authors have read and approved the manuscript.

\section{Funding}

Institutional funding was received for this study. The funder had no role in the design, collection, analysis and interpretation of the data in this study. Open Access funding enabled and organized by Projekt DEAL.

\section{Availability of data and materials}

The datasets used and/or analyzed during the current study is available in the zenodo respiratory, https://doi.org/10.5281/zenodo.5136291.

\section{Declarations}

\section{Ethics approval and consent to participate}

Ethics approval was granted from Ethics Committee of the Albert-LudwigsUniversity Freiburg, Germany (approval number 481/19). Written consent was obtained from all participants.

\section{Consent for publication}

Not applicable.

\section{Competing interests}

The authors declare that they have no competing interests.

\section{Author details}

${ }^{1}$ Faculty of Medicine, Eye Center, University of Freiburg, Killianstrasse 5, 79106 Freiburg, Germany. ${ }^{2}$ Institute of Anatomy, Wuerzburg University, Wuerzburg, Germany. ${ }^{3}$ Faculty of Medicine, Department of Medicine II, Gastroenterology, Hepatology, Endocrinology and Infectious Disease, University Medical Center Freiburg, Freiburg, Germany. ${ }^{4}$ Department of Ophthalmology, Semmelweis University, Budapest, Hungary.

Received: 30 April 2021 Accepted: 2 September 2021

Published online: 20 September 2021

\section{References}

1. Messmer EP, Font RL. Applications of Immunohistochemistry to Ophthalmic Pathology. Ophthalmology 1 Juni. 1984;91(6):701-7.

2. Tsurui H, Nishimura H, Hattori S, Hirose S, Okumura K, Shirai T. Seven-color Fluorescence Imaging of Tissue Samples Based on Fourier Spectroscopy and Singular Value Decomposition. J Histochem Cytochem 1 Mai. 2000; 48(5):653-62.

3. Bandura DR, Baranov VI, Ornatsky OI, Antonov A, Kinach R, Lou X. u. a. Mass Cytometry: Technique for Real Time Single Cell Multitarget Immunoassay Based on Inductively Coupled Plasma Time-of-Flight Mass Spectrometry. Anal Chem 15 August. 2009;81(16):6813-22.

4. Lou X, Zhang G, Herrera I, Kinach R, Ornatsky O, Baranov V. u. a. PolymerBased Elemental Tags for Sensitive Bioassays. Angew Chem Int Ed Engl. 2007;46(32):6111-4.

5. Schulz D, Zanotelli VRT, Fischer JR, Schapiro D, Engler S. Lun X-K, u. a. Simultaneous Multiplexed Imaging of mRNA and Proteins with Subcellular Resolution in Breast Cancer Tissue Samples by Mass Cytometry. Cell Syst 24 Januar. 2018;6(1):25-36.e5.

6. Giesen C, Wang HAO, Schapiro D, Zivanovic N, Jacobs A, Hattendorf B. u. a. Highly multiplexed imaging of tumor tissues with subcellular resolution by mass cytometry. Nat Methods April. 2014;11(4):417-22.

7. Mei HE, Leipold MD, Maecker HT. Platinum-conjugated antibodies for application in mass cytometry. Cytometry Part A. 2016;89(3):292-300.

8. Damond N, Engler S, Zanotelli VRT, Schapiro D, Wasserfall CH, Kusmartseva I. u. a. A Map of Human Type 1 Diabetes Progression by Imaging Mass Cytometry. Cell Metab. 2019;05(3):755-68.e5. 29.

9. Sommer C, Straehle C, Köthe U, Hamprecht FA. Ilastik: Interactive learning and segmentation toolkit. In: 2011 IEEE International Symposium on Biomedical Imaging: From Nano to Macro. 2011. S. 230-3.


CellProfiler: image analysis software for identifying and quantifying cell phenotypes. Genome Biol. 2006;7(10):R100.

11. Schapiro D, Jackson HW, Raghuraman S, Fischer JR, Zanotelli VRT, Schulz D. u. a. histoCAT: analysis of cell phenotypes and interactions in multiplex image cytometry data. Nat Methods September. 2017;14(9):873-6.

12. Amir ED, Davis KL, Tadmor MD, Simonds EF, Levine JH, Bendall SC. u. a. viSNE enables visualization of high dimensional single-cell data and reveals phenotypic heterogeneity of leukemia. Nat Biotechnol Juni. 2013;31(6):54552.

13. Levine JH, Simonds EF, Bendall SC, Davis KL, Amir ED, Tadmor M. u. a. Datadriven phenotypic dissection of AML reveals progenitor-like cells that correlate with prognosis. Cell 2 Juli. 2015;162(1):184-97.

14. Cao J, Brouwer NJ, Richards KE, Marinkovic M, van Duinen S, Hurkmans D. u. a. PD-L1/PD-1 expression and tumor-infiltrating lymphocytes in conjunctival melanoma. Oncotarget 15 August. 2017;8(33):54722-34. 
15. Lassalle $\mathrm{S}$, Nahon-Esteve $\mathrm{S}$, Frouin E, Boulagnon-Rombi C, Josselin N, Cassoux N. u. a. PD-L1 Expression in 65 Conjunctival Melanomas and lts Association with Clinical Outcome. Int J Mol Sci. 30. November 2020;21 (23).

16. Gerdes J. Ki-67 and other proliferation markers useful for immunohistological diagnostic and prognostic evaluations in human malignancies. Semin Cancer Biol Juni. 1990;1(3):199-206.

17. Holness CL, Simmons DL. Molecular cloning of CD68, a human macrophage marker related to lysosomal glycoproteins. Blood 15 März. 1993;81 (6):1607-13.

18. Hamilton NB, Attwell D, Hall CN. Pericyte-mediated regulation of capillary diameter: a component of neurovascular coupling in health and disease. Front Neuroenergetics [Internet]. 2010 [zitiert 13. Oktober 2020];2. Verfügbar unter: https://www.frontiersin.org/articles/https://doi.org/10.3389/fnene.201 0.00005/full.

19. Grant RI, Hartmann DA, Underly RG, Berthiaume A-A, Bhat NR, Shih AY. Organizational hierarchy and structural diversity of microvascular pericytes in adult mouse cortex. J Cereb Blood Flow Metab. 2019;39(3):411-25.

20. Bontkes HJ, de Gruijl TD, Walboomers JM, van den Muysenberg AJ, Gunther AW, Scheper RJ. u. a. Assessment of cytotoxic T-lymphocyte phenotype using the specific markers granzyme B and TIA-1 in cervical neoplastic lesions. Br J Cancer. 1997;76(10):1353-60.

21. Jakobiec FA, Bhat P, Colby KA. Immunohistochemical studies of conjunctival nevi and melanomas. Arch Ophthalmol Februar. 2010;128(2):174-83.

22. Soon AK, Brownstein S, Tang T, Saleh S, Jiang K, Levac J. u. a. Immunohistochemical analysis of benign and malignant melanocytic lesions of the conjunctiva using double-staining. Can J Ophthalmol Dezember. 2019:54(6):699-707.

23. Milman T, Zhang Q, Ang S, Elder D, Ida CM, Salomao DR. u. a. Conjunctival nevi and melanoma: multiparametric immunohistochemical analysis, including p16, SOX10, HMB45, and Ki-67. Hum Pathol September. 2020;103:107-19.

24. Ramirez-Miranda A, Nakatsu MN, Zarei-Ghanavati S, Nguyen CV, Deng SX. Keratin 13 is a more specific marker of conjunctival epithelium than keratin 19. Mol Vis. 2011;17:1652-61.

25. Krenzer KL, Freddo TF. Cytokeratin expression in normal human bulbar conjunctiva obtained by impression cytology. Invest Ophthalmol Vis Sci Januar. 1997;38(1):142-52.

26. Han W, Hu C, Fan Z-J, Shen G-L. Transcript levels of keratin 1/5/6/14/15/16/ 17 as potential prognostic indicators in melanoma patients. Sci Rep 13 Januar. 2021;11(1):1023

27. Porta Siegel T, Hamm G, Bunch J, Cappell J, Fletcher JS, Schwamborn K. Mass Spectrometry Imaging and Integration with Other Imaging Modalities for Greater Molecular Understanding of Biological Tissues. Mol Imaging Biol. 2018;20(6):888-901.

28. Ijsselsteijn $M E$, van der Breggen $R$, Farina Sarasqueta A, Koning F, de Miranda NFCC. A 40-Marker Panel for High Dimensional Characterization of Cancer Immune Microenvironments by Imaging Mass Cytometry. Front Immunol [Internet]. 29. Oktober 2019 [zitiert 30. Oktober 2020];10. Verfügbar unter: https:/www.ncbi.nlm.nih.gov/pmc/articles/PMC6830340/.

29. Wang F, Flanagan J, Su N, Wang L-C, Bui S, Nielson A. u. a. RNAscope: a novel in situ RNA analysis platform for formalin-fixed, paraffin-embedded tissues. J Mol Diagn Januar. 2012;14(1):22-9.

30. Chang Q, Ornatsky OI, Siddiqui I, Loboda A, Baranov VI, Hedley DW. Imaging Mass Cytometry Cytometry Part A. 2017;91(2):160-9.

31. Baharlou H, Canete NP, Cunningham AL, Harman AN, Patrick E. Mass Cytometry Imaging for the Study of Human Diseases-Applications and Data Analysis Strategies. Front Immunol. 2019;10:2657.

\section{Publisher's Note}

Springer Nature remains neutral with regard to jurisdictional claims in published maps and institutional affiliations.

Ready to submit your research? Choose BMC and benefit from:

- fast, convenient online submission

- thorough peer review by experienced researchers in your field

- rapid publication on acceptance

- support for research data, including large and complex data types

- gold Open Access which fosters wider collaboration and increased citations

- maximum visibility for your research: over $100 \mathrm{M}$ website views per year

At $\mathrm{BMC}$, research is always in progress.

Learn more biomedcentral.com/submissions 